\title{
Research on the Upgrading Path of Emerging Industry Innovation Service Network
}

\author{
Li Yue ${ }^{1 a}$, Xu Huijie ${ }^{1 b}$, Zhou Yan*1c \\ ${ }^{1}$ School of Economics and Management, Harbin University of Science and Technology, Harbin, China
}

\begin{abstract}
Innovation service network is the inevitable result of the collaborative cooperation of innovation service subjects, and also an important strategic resource for innovation activities in emerging industries. The research of innovation service network has important decision reference value for the promotion of collaborative service capability for the innovation demand of emerging industries. By analyzing the evolution process and law of innovation service network in emerging industries, improving the main line around the ability of collaborative service, combining the evolution stage of innovation service network, the complexity of innovation demand and the integration of service resources, this paper focuses on designing the upgrade path of innovation service network based on key nodes, the path of innovation service network upgrade based on service chain integration, and the upgrade path of innovation service network based on core network coordination, in order to optimize the structure of innovation service network of emerging industries and improve its ability of collaborative service provides theoretical guidance, which is of great practical significance to support the innovation and development of emerging industries.
\end{abstract}

\section{INTRODUCTION}

The Outline of the National Innovation-Driven Development Strategy proposes a "three-step" strategy, that is, china will become an innovative country by 2020 , a leading innovative country by 2030 and a world-class scientific and technological innovation power by 2050[1] In order to achieve these goals, industries with great innovation vitality are incorporated into China's strategic emerging industries, which are the key to promoting the strategic deployment of industrial innovation[2-3].

With innovation-driven development strategies, innova-tion services have come into being. Innovation services are services for innovative activities such as research and development services, intellectual property services and advanced technology services. The main subjects of inno-vation services include science and technology interme-diary[4-5], innovation service platform[6], science and technology resource sharing platform[7], and knowledge service intermediary[8]. The combination of resources and service advantages provides appropriate service support for industrial innovation in order to effectively improve the efficiency of industrial innovation[9].

For all kinds of innovation needs, collaborative coopera-tion among innovation service subjects has gradually shown the characteristics of "multiple, dynamic and complex" network. Ellerml et al. (2004) emphasized the importance of science and technology intermediaries from the perspective of chain, believing that chain is conducive to science and technology intermediaries to serve other upstream and downstream connections and to promote the comprehensive development of innovative services [10]. Howells (2006) analyzed technology intermediary service and innovation activity mechanism from the perspective of "inter-chain relationship" [11]. Lin Lei (2014) constructed the technology intermediary service chain based on the innovation chain [12]. From the perspective of innovation chain, Wang Jifa (2015) constructed the chain structure model of science and technology service industry. Based on its overall structure and value realization process, he proposed that service chain construction should be matched with innovation chain [13]. Xia Houxue et al. (2017) held that as the supplier of innovative services, the new industrial innovation platform would be transformed from "embedded" in the industrial organization system to "integrated" in the intelligent production and service network system [14]. Li Yue et al. (2020) simulated the evolution process of innovation service network with the help of complex network, and the results showed that the evolution of innovation service network can be divided into three stages: emerging[15], growth and maturity [15].

The network relationship between innovation service subjects such as science and technology intermediary, research institution, science and technology service platform and financial institution accelerates the flow of innovation resources between regions and promotes the efficient alloca-tion of innovation resources. Therefore, how to define the innovation service network, analyze the evolution stage of the network, and how to improve the collaborative service ability and upgrade the network in the process of the evolution of the innovation service network are all important issues that need to be solved urgently in the process of the development of the innovation service network. 


\section{THE EVOLUTION LAW OF INNOVATION SERVICE NETWORK IN EMERGING INDUSTRIES}

Emerging industry innovation service network refers to the relationship network formed in the process of resource docking and service matching by the relevant subjects with the function of science and technology service, such as science and technology intermediary, research institution, service platform and financial institution, which are around the demand of the innovation chain of emerging industries. The innovation service network covers scientific research and experimental development services, specialized technical services, technology promotion services, science and techno-logy information services, science and technology financial services, science and technology popularization and publicity and education services, integrated science and technology services and other service functions. Emerging industry innovation service network has experienced three stages of evolution: emerging[15], growth and maturity[15], as shown in Fig. 1.

- Emerging. At first, due to the limited resources of industrial innovation, innovation service network seeks for service subjects with complementary capabilities to support RESEARCH and develo-pment, technology and other services, resulting in professional division of labor and spillover effects. In this stage, the cooperation between network subjects is relatively simple and time-limited, and the cooperative service activities are not frequent enough. Each service subject does not fully play its role, but simply superimposes the simplest service.

- Growth. The cooperation content of network subjects is gradually broad, the degree of coopera-tion is gradually deepened, and the division of labor within the network is refined and specialized. At the same time, professional service institutions such as science and technology intermediaries and financial institutions have been gradually improved, the service attributes of universities and research institutes have begun to appear, and the interaction between network subjects has gradually become frequent. At this stage, the basic elements such as nodes and connection relations in the innovative service network have been improved, resources can flow rapidly and effectively, network subjects enjoy the spillover effect of resources such as knowledge, and industrial innovation ability has also been improved accordingly

- Maturity. Network subjects continue to carry out collaborative services, the service attributes of research institutions become more and more obvious, and a good environment for collaborative service innovation in core networks and peripheral networks is formed. In the innovation service network, knowledge, information, capital and other resources flow frequently, forming a good atmos-phere of knowledge sharing and cross-learning, and active service innovation activities. At this stage, the network structure tends to be stable and the service capacity is greatly improved. However, with the intensification of competition among similar subjects, zombie subjects and inferior subjects in the original innovation service network will not be able to meet the needs of the development and upgrading of the innovation service network, and will be replaced by new subjects, which will be eliminated by the network and the related connections will also disappear.

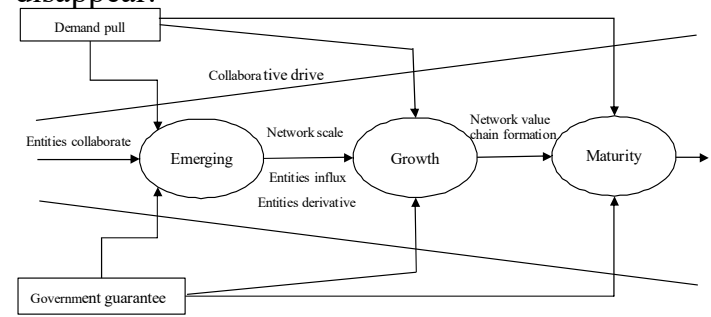

Figure 1. A diagram of the evolution of the innovation service network

\section{CONSTRUCTION OF UPGRADING PATHS FOR INNOVA-TION SERVICE NETWORKS IN EMERGING INDUSTRIES}

Emerging industry innovation service network has gone through three stages of evolution, emerging, growth and maturity, each of which has different network structure and collaborative service capability. Emerging industry innova-tion service network needs to adjust its own upgrade path freely and flexibly according to the specific innovation demand, the state of service resources and the stage of evolution and development. Therefore, this paper combines the evolution stage of innovation service network, the complexity of innovation requirements and the degree of service resource integration, from point to line to face to design the innovation service network upgrade path, that is, the innovation service network upgrade path based on key nodes, the innovation service network upgrade path based on service chain integration and the innovation service network upgrade path based on core network collaboration, the relationship between the three upgrade paths is shown in Fig. 2.



Figure 2. Emerging industry innovation service network upgrade path relationship model 


\section{A. Upgrading path of innovation service network based} on the cultivation of key nodes

The upgrading path of innovation service network based on the cultivation of key nodes is to guide service innova-tion, identify prominent nodes and cultivate key nodes of the original innovation service network according to the innovation demand through the plan, organization and support of the government, so as to form a growth pole within the innovation service network When key nodes become cultivated objects for a new round of construction and development, in the interaction process within the innovation service network, they gradually become the core of the network, radiating and driving the surrounding and upstream and downstream nodes, and promoting the upgrading of the entire network structure and function, as shown in Fig. 3.

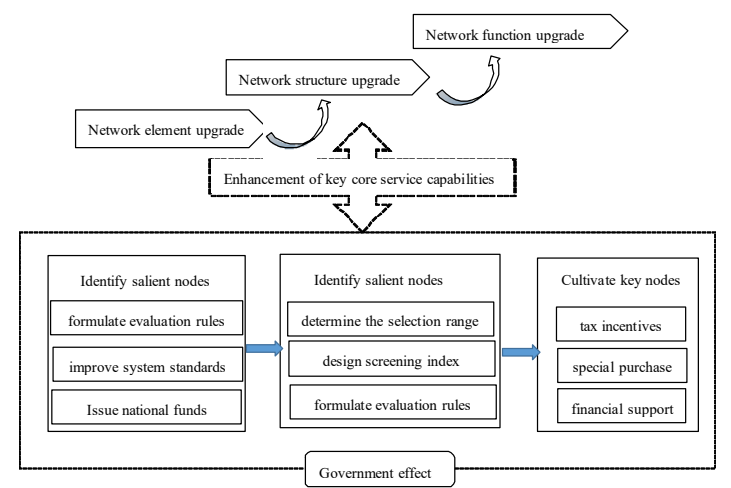

Figure 3. Innovation service network upgrade path based on key nodes

\section{B. Upgrading path of innovation service network based on service chain integration}

The upgrading path of innovation service network based on service chain integration is the key node of innovation service network to reduce service cost and improve service efficiency as the goal, interconnect, form a cooperative and intensive service chain, through the integration of the main body on the service chain, attract both sides of the main body to the service chain, thus driving the process of network function upgrade. Service chain is around the service core enterprises, the use of modern information technology, through the chain of capacity flow, information, as shown in Fig. 4.

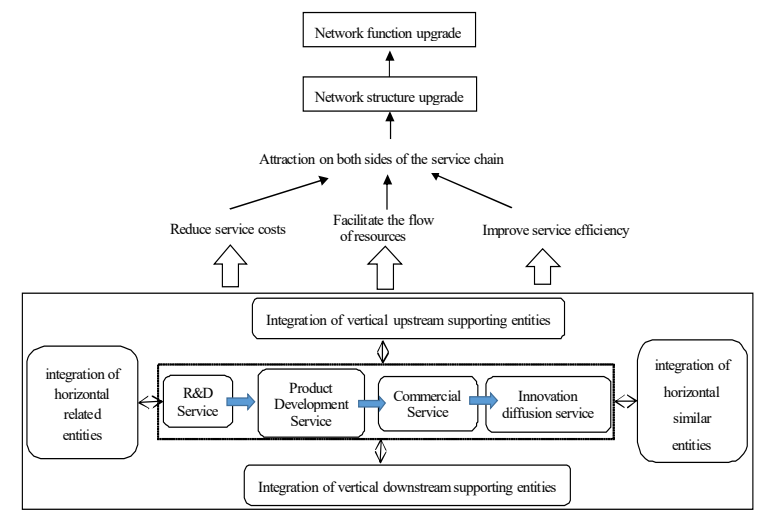

Figure 4. Innovation service network upgrade path based on service chain integration

\section{Upgrading path of innovation service network based on core Network collaboration}

The upgrading path of innovation service network based on the core network coordination refers to the process of the innovation service with predictability and advanced service under the role of the core network synergy benefit, which relies on the innovation service elements such as financial resources, information resources and human resources of the innovation service network. The innovation service network upgrade path based on core network synergy puts forward service innovation requirements for all the main bodies in the network, and promotes the innovation service network to become a intelligent complex of cohesive service innovation through multidirectional collaborative development and organic integration, the specific upgrade process is shown in Fig.5.

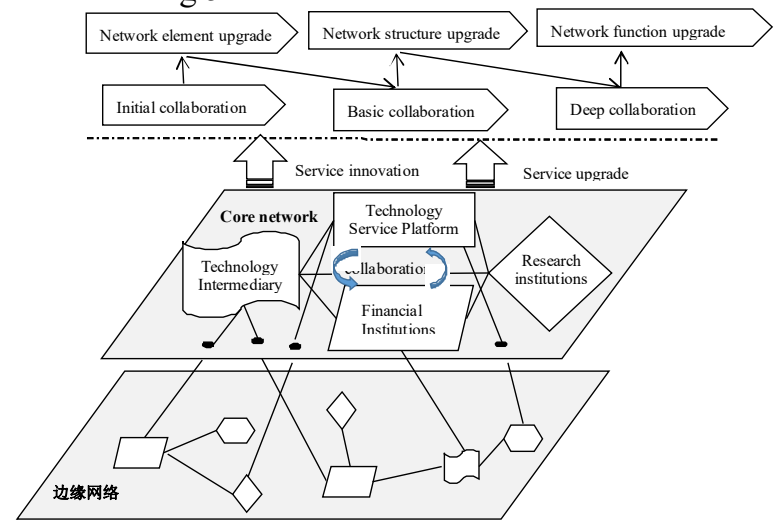

Figure 5. Innovation service network upgrade path based on core network collaboration

\section{CONCLUSIONS AND COUNTERMEASURES}

Emerging industries innovation service network is the main support of industrial innovation related services and an important strategic resource for the high-quality develop-pment of emerging industries. On the basis of innovative service network evolution rules, implement the upgrade path, innovative services and network integration advantage res-ources, adapt to the need of the new industry innovation, form a specialization, integration and intelligent service capability of innovation, promote the emerging industry continues to develop ecological innovation service system, provide efficient service support for the emerging industry innovation. Therefore, based on the research, the following strategies are proposed for the development of innovative service networks in emerging industries:

1) Strengthen the cultivation of the core nodes based on the platform

Science and technology service platform plays the role of network resource flow hub in the evolution process of innovation service network, and is the central hub of innova-tion service network, further accelerating the flow of resources and services between networks, and improving the collaborative service ability of integrated innovation service network. 
2) Cultivate the service ability of the innovation subject

In the process of the evolution of innovation service network, some research institutions from research to application-oriented transformation, with the deepening of the reform of the research institute system, there will be some research institutes from research-oriented to application-oriented, actively participate in commercialization or directly related to the economy of the project, began to connect the market and innovation needs, more and more reflect its service attributes.

3) Improve the policy support system for innovation services

There are obvious differences in the effects of govern-ment in different stages of innovation service network evolution. The evolution of innovation service network is the result of the interaction of internal and external environmental factors, in which the government has a significant influence on the evolution of innovation service network at all stages, especially in the germination and growth stage of the network.

\section{ACKNOWLEDGMENT}

This research was supported by the National Natural Science Foundation of China (No. 71704036), the Philosophy and Social Sciences Research Planning Project of Heilongjiang Province (No. 20GLB119; No. 19GLB327), and the Outstanding Young Talent Project of Talents Plan of Harbin University of Science and Technology (No. 2019-KYYWF-0216).

\section{REFERENCES}

1. M. K. Sheng and J. Luo, "Comparative research on strategy and policy of science and technology innovation between china and india - take STI in India and China's "outline of nation innovation-driven develoment strategy" as an example," Science \& Technology progress and policy, vol. 35, pp. 127-134, 2018.

2. Y. Li, H. Guo, S. Y. Cooper and H. Q. Wang, "The influencing factors of the technology standard alliance collaborative innovation of emerging industry", Sustainability, vol. 11, no. 24, pp. 1-17, 2019

3. J. Wu, Z. Yang, X. Hu, H. Wang and J. Huang, "Exploring driving forces of sustainable development of China's new energy vehicle industry: an analysis from the perspective of an innovation ecosystem," Sustainability, vol. 10, no. 12, pp. 1-24, 2018.

4. Villani, E. Rasmussen and R. Grimaldi, "How intermediary organizations facilitate university - industry technology transfer: a proximity approach," Technological Forecasting and Social Change, vol. 114, pp. 86-102, 2017.

5. F. Stezano, "The role of technology centers as intermediary organizations facilitating links for innovation: four cases of federal technology centers in Mexico," Review of Policy Research, vol. 35, no. 4, pp. 642-666, 2018.

6. W. Fu, Q. Wang and X. Zhao, "The influence of platform service innovation on value co-creation activities and the network effect," Journal of Service Management, vol. 28, no. 2, pp. 348388, 2017.

7. K. Hong, J. R. Hu and W. Wang, "Research on the innovative clusters and countermeasures of scince $\&$ technology information resource sharing platform kunming, Chengdu platform as an example," 5th International Conference on Cooperation and Promotion of Information Resources in Science and Technology, pp. 386-391, 2010.

8. T. Abbate, A. P. Codini and B. Aquilani, "Knowledge co-creation in Open innovation digital platforms: processes, tools and services," Journal of Business \& Industrial Marketing, vol. 34, no. 7, pp. 1434-1447, 2019.

9. V. Eloranta and T. Turunen, "Platforms in service-driven manufacturing: Leveraging complexity by connecting, sharing, and integrating," Industrial Marketing Management, 2015, no. 10 pp. 1-9.

10. M. Ellraml, T. Wendyl and B. Corey, "Understanding and managing the service supply chain," Journal of supply china management, 2004 , no. 22 , pp. 17-32.

11. J. Howells, "Intermediations in the role of intermediaries in innovation," Research Policy, 2006, no. 35, pp. 609-766.

12. L. Lin, J. Wu and P. Wang, "Symbiosis and Coupling between S\&T Intermediary Service Chain and Innovation Chain Theory Building and Policy Implication," Technology economics, 2014, vol. 33 , no. 6 , pp. 7-13.

13. J. Wang, H. Ao and H. Chen, "The research of chain structure and value realization mechanism Based on Innovation Chain in s\&t service Industry," Science Technology Progress and Policy, 2015, vol. 32, no.15, pp. 59-63.

14. H. Xia, Q. Tan, B. Wang, "A study of a new type of industry innovation platform for high-end oriented equipment manufacturing industry from the perspective of intelligent production and service network," Science research management, 2017, vol. 12, no. 38, pp. 1-10.

15. Y. Li, Y. Zhou, H. Wang and C. Wu, "Research on the Evolution of Regional Strategic Emerging Industry Innovation Service Network based on Improved BBV Mode," Forecasting, 2020, vol. 39 , no. 5,pp. 89-96. 